\title{
Philosophical Expertise Put to the Test
}

\author{
Samuel Schindler and Pierre Saint-Germier
}

forthcoming in the Australasian Journal of Philosophy

\begin{abstract}
The so-called expertise defence against sceptical challenges from experimental philosophy has recently come under attack: there are several studies claiming to have found direct evidence that philosophers' judgments in thought experiments are susceptible to erroneous effects. In this paper we distinguish between the customary 'immune experts' version of the expertise defence and an 'informed experts' version. On the informed expertise defence, we argue, philosophers' judgments in thought experiments could be preferable to the folks' even if it were true that philosophers' judgments are no less immune to confounders than the folk's. We present results from an experimental study comparing philosophers and non-philosophers $(n=484)$, which, we argue, supports this version of the expertise defence.
\end{abstract}

Keywords: philosophical expertise, expertise defense, method of cases, experimental philosophy, thought experiments, skills

\section{Introduction}

Experimental philosophers have found that judgments in philosophical cases, or case judgments for short, vary with all kinds of prima facie extraneous factors, such as socioeconomic status, gender, order of presentation, cultural background, and more [Alexander and Weinberg 2007; Machery 2017]. ${ }^{1}$ From these results, some have concluded that case judgments and the method of cases, namely the method of using judgments in thought experiments as evidence in philosophical theorizing, is unreliable [Alexander and Weinberg 2007; Machery 2017]. Critically, much of the claim about the general unreliability of case judgments is based on an induction from experiments with subjects with little or

\footnotetext{
${ }^{1}$ Case judgments have more commonly been referred to as 'intuitions', but there are good reasons not to use psychological descriptions. See e.g., Williamson [2007, 2011] and Machery [2017].
} 
no philosophical training, also known as 'the folk'. ${ }^{2}$ Champions of the traditional philosophical methodology have accordingly sought to block this inductive inference by arguing that the folk are not as competent as philosophers are in making case judgments. This reply is known as the expertise defence and is thought by many to be the most promising way of reacting to the sceptical challenge posed by experimental philosophers [Hales 2006; Ludwig 2007; Williamson 2007; Horvath 2010; Devitt 2011; Williamson 2011].

There has been experimental work which has directly tested the reliability of case judgments by philosophers especially in moral cases [Schulz et al. 2011; Feltz and Cokely 2012; Schwitzgebel and Cushman 2012; Tobia et al. 2013; Schwitzgebel and Cushman 2015; Löhr 2019; Alexander Wiegmann et al. 2020; Alex Wiegmann and Horvath forthcoming], but also in other areas of philosophy, such as semantics [Machery 2012] and epistemology [Vaesen et al. 2013; Horvath and Wiegmann 2016; Starmans and Friedman 2020]. These results have led some to conclude that philosophical expertise in making case judgments is 'largely a myth' [Horvath and Koch forthcoming].

The debate about the challenge from experimental philosophy has focused much on whether or not philosophers too - rather than just the folk - would exhibit susceptibility to confounders, such as the order of presentation or cultural background, that is factors that arguably should not affect case judgments [Machery 2017]. Call the version of the expertise defence which denies or minimizes such susceptibility to confounders the immune expertise defence [Devitt 2011; Williamson 2011]. But there is yet another version of the expertise defence, which we want to advance in this paper.

Thought experimentation, we argue here, requires certain skills. The execution of those skills, we will say, results in case judgments that are informed and informative. By the former we mean that case judgments are based on information that is essential for the proper assessment of thought experiments. When case judgments are informed in this way they are then also informative in the sense of being apt to tell us something about the relevant philosophical content of thought experiments, rather than about something else. If the case judgments of philosophers are more informed and informative than the folk's,

\footnotetext{
2 In his recent book, Machery summarizes much of the experimental work to date in a chapter titled 'the empirical findings' [Machery 2017]. All of these findings are experiments with the folk.
} 
then philosophers' case judgments would be preferable to the folk's. We call this the informed expertise defence.

True to the spirit of the armchair critics, we here present results of a larger experimental study that pit philosophers against non-philosophers with regards to three skill tasks. Our results indicate that philosophers' case judgments are indeed more informed and informative than the folk's.

Here is how we will proceed: In section 2, we discuss extant views of philosophical expertise and identify three skills which we consider essential for making informed and informative case judgments. In section 3, we present the hypotheses of our experiment and in section 4 we describe our methods. Section 5 contains the results of our experiments and a discussion. Section 6 contains the discussion of our results and the conclusion of this paper. There we also outline the relationship between the informativeness of case judgments and their potential bias.

\section{What makes case judgments informed and informative?}

A common view amongst proponents of the expertise defence is that philosophers are better at applying concepts to cases than the folk [Ludwig 2007; Horvath 2010; Williamson 2011]. Machery [2017] provides a comprehensive criticism of this view (which he calls the 'mastery model') and offers another interpretation of philosophical expertise: the 'thought experimentation model'. According to this model, philosophers may be said to be better than the folk at 'ignoring the irrelevant (e.g., narrative) aspects of thought experiments and at singling out their pertinent features' (Machery [2017: 158]; see Weinberg et al. [2010: 348]). Machery makes short shrift of this interpretation of philosophical expertise, but we actually consider this version the more promising one of the two. ${ }^{3}$ In what follows we therefore focus on the thought experimentation model of expertise when identifying skills we consider important for making informed and informative case judgments.

\subsection{Three skills for informed case judgments}

Machery [2017] makes a further distinction that we used in our identification of skills relevant for the informed expertise defence: he distinguishes between the 'target' and the

\footnotetext{
${ }^{3}$ Machery finds the thought experimentation model not plausible mostly because students are not explicitly taught what a good thought experiment consists in. But surely, there is a lot of implicit learning through repeated exposure to paradigm cases.
} 
'superficial' content of a thought experiment. The superficial content of a thought experiment, for Machery, concerns 'the narrative setting of the philosophical case' and consists of 'facts and non-factual (e.g., emotional) connotations that do not matter from a philosophical point of view; it varies across versions of a given case' (13). The target content, in contrast, consists of 'facts and non-factual connotations that matter from a philosophical point of view; it is invariant across versions of a case' (13). To illustrate, the superficial content of Gettier cases can be very dissimilar: some involve malfunctioning clocks that accidentally indicate the correct time, others the misidentification of who in one's office in fact owns a Ford. The target content of any Gettier case, however, always involves an agent who has justified true beliefs that $X$ by luck [Zagzebski 1994].

Machery's distinction suggests two relevant - and related - skills for making informed and informative case judgments: (i) the ability to comprehend the target content and (ii) the ability to distinguish the target content from the superficial content. For example, in a famous version of the Gettier case, for one's case judgment about whether or not Smith knowns to be informed and informative, one must be able to comprehend that Smith has justified true belief. If one were to not to understand that Smith's true belief is justified, for example, then one's judgment about this Gettier case wouldn't be fully informed and therefore not as valuable as the judgments by subjects who fully comprehend the target content. Likewise, in Gödel-Schmidt cases, subjects must understand that Gödel, contrary to actual fact, is stipulated not to have proven the incompleteness of arithmetic. Subjects who do not understand this element of the scenario can still make a judgment about whether the name 'Gödel' refers to the individual Gödel, but their judgments will not be as informative as the judgments by subjects who do understand this presupposition of the thought experiment.

There is some evidence that a difference in the ability to comprehend the target content could be part of philosophers' expertise. For example, Turri [2013] found that the folk's failure to make the standard Gettier judgment has something to do with them not understanding three basic steps of the thought experiment (first justified belief, then bad luck prevents belief from being true, and finally good luck makes the belief true anyway). Although it has become customary in philosophical studies to exclude subjects on the basis of them failing comprehension questions (see for example Starmans and Friedman [2012, 2020]), such an exclusion may conceal one dimension of philosophers' expertise. 
The exclusion criteria that have been used may exclude too many data anyway [Bergenholtz et al. 2021].

The second skill we identified, namely the ability to distinguish the target content from the superficial content, is required for subjects to extract the target content not only across superficially varying cases (as suggested by Machery's definition), but also in individual cases. For example, in the standard Gettier case, one must understand that Jones renting a Ford rather than just occasionally driving Brown's Ford is irrelevant to the case judgment of whether or not Smith knows that Jones owns a Ford when having (accidental) justified true belief that he does. Likewise, in Jackson's Mary the Scientist, one must understand that it's quite irrelevant to the case judgment that Mary knows 'all the physical information there is to obtain about what goes on when we see ripe tomatoes', rather than for example red cars [Jackson 1982].

The first and the second skill we identified are of course related. However it is perfectly possible that one may fully comprehend the entire content of a thought experiment without being able to tell apart the target from the superficial content. Conversely, one may be able to tell apart the two contends, but then still make mistakes in comprehending the content. We therefore kept the two skills separate in our analysis.

A third ability we take to be important for making informed and informative case judgments is briefly alluded to by Williamson: 'one must also judge whether the scenario is really possible, for otherwise the thought experiment may not be fit for purpose [of refuting a philosophical view]' [Williamson 2011, 224]. What does it mean for a scenario of thought experiment to be 'really possible'? In many cases it means that the scenario is merely logically, conceptually, or metaphysically possible, rather than physically possible. ${ }^{4}$ For example, it may be physically impossible to do the brain swaps envisioned by thought experiments in the personal identify literature, and it may not be possible to keep somebody alive by being 'hooked up' to them, as envisaged by Thomson's violinist thought experiment, etc. An inability to consider a wider range of possibilities will block one from making the relevant informed and informative case judgments.

\footnotetext{
${ }^{4}$ How exactly these kinds of possibilities are to be individuated (if at all) is a matter of dispute. See Vaidya [2017] for more on different kinds of modalities and their epistemology.
} 
Even a sceptic of metaphysical modality such as Machery points out that it important that 'budding philosophers' are made aware of the fact that twin earth is not meant to be actual [Machery 2017: 162]. More specifically, if one is not able to understand or accept that the watery substance on twin earth is a metaphysical possibility, and if one insists that substances that possess all the 'superficial' qualities of water must be $\mathrm{H}_{2} \mathrm{O}$ (as in the actual world), then one will not be in a position to judge informatively whether or not people on twin earth refer to water when they talk about the watery substance on twin earth. It is then no surprise that important models of thought experimentation require the acceptance of a possibility premise [Williamson 2007; Häggqvist 2009]. Thus, the third ability making informed and informative case judgments is the following:

(3) The ability to accept that the scenarios described in the vignette can be (metaphysically, conceptually, or logically) possible, even when they are not nomologically possible.

It's quite obvious that philosophers are much more used to pondering the 'unusual' scenarios of thought experiments than the folk. One may therefore expect that philosophers, on average, are more willing than the folk to accept the possibility of scenarios of thought experiments - at least for the sake of the argument.

In sum, we find it plausible that the ability to comprehend the target content of thought experiments, the ability of telling apart the target and the superficial content of thought experiments, and the ability to accept (metaphysical) possibilities are critical for making informed and informative case judgments.

\section{Hypotheses}

In our study, we tested altogether five hypotheses: they fall into three categories. First, we wanted to know whether philosophers are better than the folk in the three skills we identified for thought experimentation:

- H1: philosophers are better at comprehending the target content of thought experiments than non-philosophers.

- H2: philosophers are better at discerning the target from the superficial content in thought experiments than non-philosophers.

- H3: philosophers are more willing to accept the possibility of thought experiments than nonphilosophers. 
Second, we wanted to know whether there is any difference between case judgements made by philosophers and the folk. Many contributions to the experimentalist literature have - at least implicitly - presumed a standard of philosophical case judgments and then exploited the folk's divergent case judgements to support sceptical conclusions about armchair philosophy. For example, Machery and colleagues presumed that the standard case judgment among philosophers in their Gödel cases is that Schmidt (not Gödel) is the discoverer of the incompleteness theorem, in agreement with the causal theory of reference [Machery et al. 2004]. More recently, Horvath and Wiegmann [2016] have explicitly used what they call the 'textbook consensus' (regarding cases from epistemology) as a quality standard for case judgements: the closer a judgment to the consensus, the better. In order to connect with those contributions, and to find out (i) whether there actually is a textbook consensus among philosophers, and (ii) whether philosophers were more likely to agree with it than the folk, we tested the following hypothesis:

- H4: philosophers are more likely to make case judgments in agreement with the philosophical textbook consensus than non-philosophers.

We emphasize, though, that for us (and the immune expertise defence) nothing hangs on the outcome of H4. In fact, we don't think anything should hang on it. To use a textbook consensus as quality standard runs the risk of begging the question against the armchair critics, because it is the very point of some of those criticisms that the textbook consensus might actually be a cultural artifact that merely keeps getting reinforced by the way we teach our students [Machery et al. 2004; Machery 2017].

Although Horvath and Wiegmann [2016] view the textbook consensus (henceforth: TBC) only as a defeasible quality standard, they claim that for the expertise defence to be supported, philosophers would have to be more likely to converge on it. While this may be true for what we called the immune expertise defence (Horvath and Wiegmann's target), a disconfirmation of $\mathrm{H} 4$ would not undermine our version of the expertise defence, that is, the informed expertise defence. If philosophers were indeed more skilled than the folk in making informed and informative case judgments, then, even if the folk showed similar levels of agreement with the TBC (contrary H4), there would still be good reason to prefer philosophers' case judgments. On the informed expertise defence, there is even a sense in which the extent of philosophers' agreement with the TBC does not 
really matter to whether or not philosophers' case judgments are to be preferred over the folk's - so long the philosophers are indeed more skilled. However a divergence of philosophers' case judgments from the TBC would certainly cast doubt on whether the TBC - in so far it exists - is justified; especially when the case judgments should turn out to be informed and informative. We therefore tested whether or not any of our three skill tasks would predict convergence of case judgments with the TBC:

- H5: subjects who do well on the three skill tasks are more likely to converge on the textbook consensus in their case judgments than subjects who don't.

In the next section, we'll outline how we went about testing the aforementioned hypotheses.

\section{Methods}

\subsection{Subjects}

In order to test these hypotheses, we tested two groups of subjects: philosophical experts (as defined by holding a $\mathrm{PhD}$ or being enrolled in a $\mathrm{PhD}$ program), which we recruited through Philos-L and targeted emails to selected departments, and-in accordance with recent practices in experimental philosophers - a group of non-philosophers recruited through Amazon Mechanical Turk. ${ }^{5}$ We first tested our philosophy subject group and then matched the number of subjects we obtained with our survey on MTurk. Of our MTurk subjects we required (via a filter) that they had at least 100 HITs (Human Intelligence Tasks on MTurk) approved prior to our study with an approval rate of more than $97 \%$. We also required that subjects would use at least 5 minutes to complete the survey. ${ }^{6}$ MTurk subjects received $\$ 5$ dollars upon completion of the experiment.

Overall, 242 philosophers and 242 non-philosophers completed the survey and satisfied our selection criteria (we excluded 172 philosophers and 70 non-philosophers). ${ }^{7}$ The median age of the group consisting of philosophers and non-philosophers was 35 and 34 , respectively. The gender distribution was 73\% males in the philosophers' group

\footnotetext{
${ }^{5}$ In the recent large scale study on the reproducibility of studies in experimental philosophy [Cova et al. 2021], it was reported that out of 39 original Xphi studies from 2003-2015, the majority (25) used students. More recent replication studies of these original studies used mostly MTurk workers (29 out of 39). ${ }^{6}$ On MTurk, after a subject completes a HIT, it must be confirmed by the requester that the task was carried out to their satisfaction.

7 We also excluded 47 MTurk subjects because of repetitive IP addresses.
} 
(reflecting the deplorable male-dominance in the field) and 59\% males in the nonphilosophers' group. See Appendix 2 for further details about subjects' backgrounds.

\subsection{Materials}

To all of our subjects, we presented modified versions of a Gettier case, Searle's Chinese Room, Mary the Scientist, a Fake Barn case, a Gödel case, and Twin Earth. We modified the superficial content of these standard cases in order to minimize recall effects (see Appendix 1 for all used scenarios). Subjects had four tasks for each thought experiment, whereby the order of the thought experiments was randomized. First, subjects were presented with a case judgment in the form of a statement. Subjects had to indicate their agreement or disagreement (on a 5-point Likert scale). We refer to this task as JUDGE. In order not to bias subjects towards agreement or disagreement, half of the JUDGE statements agreed with the TBC and the other half didn't. Subjects were then presented (in this order) with a task testing their understanding of relevant/irrelevant content (R/IRR), their comprehension of the target content (COMP), and the willingness to accept the possibility of the presented scenario (POSS). Each of those tasks was presented on a separate screen and the scale for each skill was a 5-point Likert scale. Subjects were reminded of the vignette at the bottom of the screen for each task. To illustrate, consider one of our six thought experiments, namely a version of the Gettier case:

John is a security guard at a warehouse. One night, the alarm bell rings. John therefore comes to believe that someone has just broken in. Unbeknownst to John, the triggering of the alarm was in fact just the result of some electronic malfunction, because the technician messed up. But as it turns out, there was actually a thief who managed to break into the warehouse at the same time when the alarm rang.

- Case judgment (JUDGE): 'To what extent do you agree or disagree with the statement 'John does not know that someone has broken into the warehouse".

- Irrelevant or relevant content $(R / I R R)$ : 'The scenario just presented to you contains the following piece of information. To what extent do you agree or disagree that the following information was important relative to that judgment? IRR: '...that the technician messed up.', or R: 'the triggering of the alarm was in fact the result of some electronic malfunction" 
- Target comprehension (COMP): 'To what extent do you agree or disagree that the following statement is correct? 'John believes that there was a break-in."'

- Possibility (POSS): 'To what extent do you agree or disagree that the described scenario is possible.'

Two clarifications about our presentation of R/IRR and POSS in order. First, each subject received either a statement about the irrelevant content of the vignette or a statement about the relevant content. We randomized those statements over the subjects. Second, the statement about the possibility of the task was left vague on purpose. Our rationale was that laypeople might by default employ a narrower notion of possibility than professional philosophers, who are very much used to ponder counterfactual scenarios, often far removed from the actual world. Accordingly, our expectation was that the folk would tend to disagree more often with the possibility statement than the philosophers would.

Why did we pick variations of standard thought experiments rather than making up our own thought experiments? First, designing thought experiments is not trivial; there is good reason why standard thought experiments are as famous and oft-used as they are. We did not want to risk derailing our study. Second, the cases we picked were cases in which expected there to be a textbook consensus, allowing us to compare subjects' case judgments accordingly (see section 3). Third, using standard thought experiments is actually conducive to our goals: the ability to recognize different guises of the same thought experiment presupposes is one of the skills that we identified as essential to philosophical expertise, namely the ability to distinguish philosophically relevant from irrelevant content.

\section{Results}

In this section we present the aggregate performances by our subjects in the three skill tasks and the JUDGE task (5.1), more fine-grained analyses of the three skill tasks and the JUDGE tasks (5.2), and test whether any of the skills is predictive of the JUDGE task (5.3). The first two parts are relevant to the testing of H1-4 and the third part to H5. 


\subsection{Overall task performance}

First we compared philosophers and non-philosophers with regard to their task performance in each of our four tasks (COMP, R/IRR, POSS, and JUDGE), by carrying out t-tests on the aggregate data. The results are as follows:

- COMP: philosophers (M=4.27, $\mathrm{SD}=1.11)$ performed significantly better than the non-philosophers $(\mathrm{M}=4.18, \mathrm{SD}=1.19), \mathrm{t}(2886.30)=1.986, \mathrm{p}=0.047$; Cohen's $\mathrm{d}=0.073$ (very small effect size) ${ }^{8}$;

- $\quad \mathbf{R} / \mathbf{I R R}$ : philosophers $(\mathrm{M}=3.35, \mathrm{SD}=1.15)$ performed significantly better than the folk $(\mathrm{M}=3.82, \mathrm{SD}=1.7), \mathrm{t}(2877.23)=7.789, \mathrm{p}<0.01$, Cohen's $\mathrm{d}=0.289$ (small effect size);

- POSS: philosophers ( $\mathrm{M}=3.76, \mathrm{SD}=1.35)$ performed significantly better than the folk $(\mathrm{M}=3.39, \mathrm{SD}=1.34), \mathrm{t}(2901.890)=7.291, \mathrm{p}<0.01$, Cohen's $\mathrm{d}=0.271$ (small);

- JUDGE: philosophers ( $M=4.07, \mathrm{SD}=1.24)$ performed significantly better than the folk $(\mathrm{M}=3.71, \mathrm{SD}=1.46), \mathrm{t}(2828.89)=7.157, \mathrm{p}<0.01$, Cohen's $\mathrm{d}=0.266$ (small).

Figure 1 depicts these results.

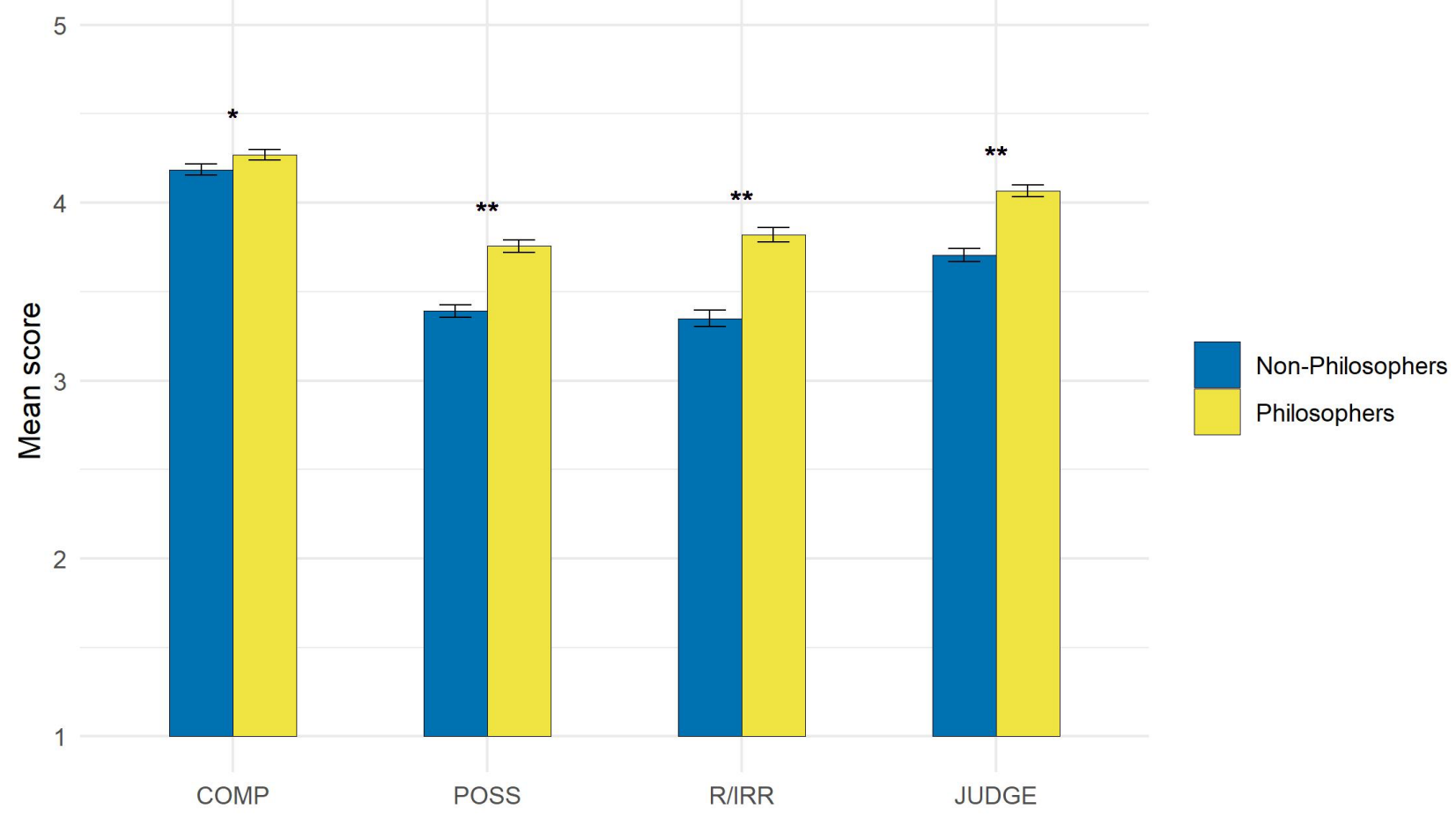

\footnotetext{
8 The effect sizes were categorized in accordance with a proposal by Hyde [2005]. According to this classification a small effect size is between 0.11 and 0.35 (exclusive), and a moderate effect size is between 0.36 and 0.65 (exclusive). See also Machery [2017: 46] for a discussion.
} 
Figure 1 Overall performance in JUDGE and the three skills tasks R/IRR, COMP, and POSS. Nonphilosophers are on the left column and philosophers on the right-hand column. Error bars indicate standard errors. T-tests uncovered significant differences for all four tasks. One star $\left.{ }^{*}\right)$ indicates a significant difference between the two groups at the $95 \%$ significance level and two stars $\left(^{* *}\right)$ at the $99 \%$ level. All effect sizes are small.

These results prima facie confirm hypotheses $\mathrm{H} 2, \mathrm{H} 3$, and $\mathrm{H} 4$. Although the COMP results are significant as well, given that the $\mathrm{p}$-value is close to the threshold for the conventional significance level, and given the effect size is very small, we do not consider $\mathrm{H} 1$ to be confirmed.

In order to find out whether any group differences between philosophers and non-philosophers in any of our four tasks depended on the scenarios, we constructed altogether four mixed ANOVA models with a 2-way interaction between groups (philosophers vs non-philosophers) and thought experiments (within subjects): one model for each type of skill task (COMP, R/IRR, POSS) and for the JUDGE task. ${ }^{9}$ All four 2-way interactions turned out to be significant, with extremely small effect sizes ${ }^{10}$ : COMP: F(4.48, 2157.96) =9.80, $\mathrm{p}<0.01, \eta^{2}=0.015 ;$ POSS: $\mathrm{F}(4.56,2199.97)=3.54, \mathrm{p}=0.005, \eta^{2}=$ 0.005. R/IRR: $F(4.76,2296.24)=3.01, p=0.01, \eta^{2}=0.005 ; J U D G E: F(4.28,2060.92)=20.38, p<$ $0.01, \eta^{2}=0.031$. Thus, the group differences in each task performance depended on the scenarios, albeit only very slightly. Given these results, we tested the group differences in the task performances for each scenario.

\subsection{Detailed results}

In this section we present the results of our experiments at a finer level of grain. We start with the three skills and then proceed with the JUDGE results.

\subsubsection{Detailed skills results}

Figure 2 depicts subjects' performance in the three skill tasks (COMP, POSS, and R/IRR) across the six thought experiments that we used. The following results are significant (see Appendix 3 for more details, including means and standard deviations) ${ }^{11}$ :

\section{- COMP: 2 in favour of the philosophers, 1 in favour of the folk}

\footnotetext{
${ }^{9}$ For each of those models we used only the data relevant to the specific task (either JUDGE, COMP, R/IRR or POSS). The dependent variables are the subjects' scores in the respective tasks.

${ }^{10}$ Cohen [1988] categorizes effect sizes of $\eta^{2}=0.01$ as small, 0.059 as medium, and 0.138 as large.

${ }^{11}$ We used Welch's t-tests which in contrast to the original Student's t-test, doesn't assume equal variance in the compared groups. Welch's t-tests computes the degrees of freedom differently, which is why the $t$ values are fractional.
} 
Mary the Scientist: philosophers $(\mathrm{M}=3.96, \mathrm{SD}=1.18)$ vs. folk $(\mathrm{M}=3.69, \mathrm{SD}=1.39)$, $\mathrm{t}(469.43)=2.332, \mathrm{p}=0.02$, Cohen's d=0.212 (small effect), Fake Barn: philosophers $(\mathrm{M}=4.45, \mathrm{SD}=0.88)$ vs. folk $(\mathrm{M}=3.85, \mathrm{SD}=1.24), \mathrm{t}(435.74)=6.13, \mathrm{p}=0.000$, Cohen's $\mathrm{d}=0.557$ (moderate effect), Twin Earth: philosophers $(\mathrm{M}=4.49, \mathrm{SD}=0.93)$ vs. folk $(\mathrm{M}=4.67$, $\mathrm{SD}=0.72), \mathrm{t}(454.28)=2.292$. $\mathrm{p}=0.022$, Cohen's $\mathrm{d}=0.208$ (small effect in favour of the folk);

- POSS: 5 in favour of the philosophers, 0 in favour of the folk

Gettier: philosophers $(\mathrm{M}=4.45, \mathrm{SD}=0.93)$ vs. folk $(\mathrm{M}=3.96, \mathrm{SD}=1.09), \mathrm{t}(462.24)=5.807$, $\mathrm{p}=0.000$, Cohen's $\mathrm{d}=0.528$ (moderate effect), Chinese Room: philosophers $(\mathrm{M}=3.32$, $\mathrm{SD}=1.33)$ vs. folk $(\mathrm{M}=3.00, \mathrm{SD}=1.26), \mathrm{t}(480.59)=2.77, \mathrm{p}=0.006$, Cohen's $\mathrm{d}=0.252$ (small effect), Mary the Scientist: philosophers $(M=2.95, S D=1.46)$ vs. folk $(M=2.40, S D=1.31)$, $\mathrm{t}(477.07)=4.328, \mathrm{p}=0.000$, Cohen's $\mathrm{d}=0.393$ (moderate effect), Fake Barn: philosophers $(\mathrm{M}=4.10, \mathrm{SD}=1.11)$ vs. folk $(\mathrm{M}=3.77, \mathrm{SD}=1.16), \mathrm{t}(480.82)=3.161, \mathrm{p}=0.002$, Cohen's $\mathrm{d}=0.287$ (small effect), Gödel: philosophers ( $\mathrm{M}=4.45, \mathrm{SD}=0.93)$ vs. folk $(\mathrm{M}=3.96, \mathrm{SD}=1.09)$, $\mathrm{t}(469.85)=5.335, \mathrm{p}=0.000$, Cohen's $\mathrm{d}=0.485$ (moderate effect);

\section{- R/IRR: 5 in favour of the philosophers, 0 in favour of the folk}

Gettier: philosophers $(\mathrm{M}=3.55, \mathrm{SD}=1.56)$ vs. folk $(\mathrm{M}=2.99, \mathrm{SD}=1.63), \mathrm{t}(481.07)=3.819$, $\mathrm{p}=0.000$, Cohen's d=0.347 (small effect), Chinese Room: philosophers $(\mathrm{M}=4.51, \mathrm{SD}=1.11)$ vs. folk (M=3.86, $\mathrm{SD}=1.67), \mathrm{t}(420.17)=5.099, \mathrm{p}=0.000$, Cohen's $\mathrm{d}=0.464$ (moderate effect), Mary the Scientist: philosophers $(\mathrm{M}=4.38, \mathrm{SD}=1.16)$ vs. folk $(\mathrm{M}=3.70, \mathrm{SD}=1.66)$, $\mathrm{t}(431.23)=5.28, \mathrm{p}=0.000$, Cohen's d=0.48 (moderate effect), Fake Barn: philosophers $(\mathrm{M}=3.48, \mathrm{SD}=1.50)$ vs. folk $(\mathrm{M}=3.14, \mathrm{SD}=1.63), \mathrm{t}(478.83)=2.41, \mathrm{p}=0.016$, Cohen's $\mathrm{d}=0.219$ (small effect), Twin Earth: philosophers ( $M=3.93, S D=1.44)$ vs. folk $(M=3.40, S D=1.69)$, $\mathrm{t}(470)=3.732, \mathrm{p}=0.000$, Cohen's $\mathrm{d}=0.339$ (small effect).

These detailed results reveal that there are hardly any differences between the two groups with regard to the COMP task (2:1 tasks in which philosophers do better than the folk), but the results also show that there a sizable advantage for philosophers in both POSS (5:0 tasks in which philosophers do better than the folk) and R/IRR (5:0 tasks in which philosophers do better than the folk). It is also worth noticing that there was overall just a single skill task, in which the folk did better than the philosophers (COMP in the twin earth thought experiment). There were five tasks in which there was no advantage for either group, three of which were COMP tasks. There was only one R/IRR task (Gödel) 
and one POSS task (twin earth) for which there was no difference between the groups (see also Appendix 3). We take these results to confirm H2 (R/IRR) and H3 (POSS), but not H1 $(\mathrm{COMP})$-in agreement with our conclusions regarding our aggregate results (see section $5.1)$.

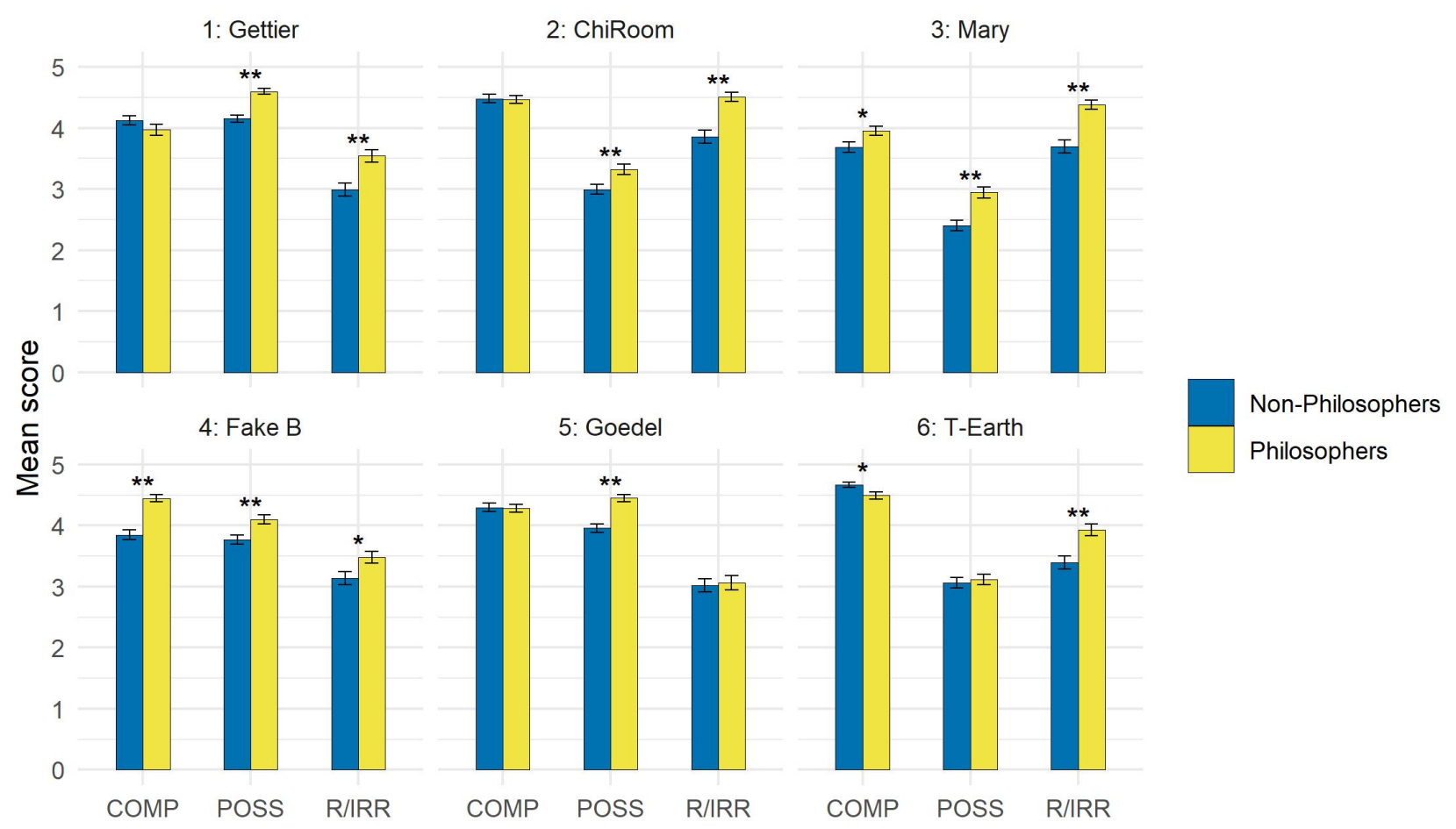

Figure 2: Individual skill tasks comparing philosophers and non-philosophers in six thought experiments (clockwise: Gettier, Chinese Room, Mary, Fake barn, Gödel, Twin Earth). Error bars indicate standard errors. One star $\left(^{*}\right)$ indicates a significant difference between the two groups at the $95 \%$ significance level and two stars $\left({ }^{* *}\right)$ at the $99 \%$ level.

\subsubsection{Detailed JUDGE results}

The individual JUDGE task performance for both philosophers and non-philosophers is depicted in Figure 3. The results are as follows: Gettier: philosophers' case judgments $(\mathrm{M}=4.15, \mathrm{SD}=1.04)$ were significantly closer to the TBC than the folk $(\mathrm{M}=3.07, \mathrm{SD}=1.38)$, $\mathrm{t}(448.57)=9.628, \mathrm{p}<0.01$, Cohen's d= 0.875 (large effect size); Chinese Room: philosophers' case judgments $(\mathrm{M}=4.77, \mathrm{SD}=1.00)$ were significantly closer to the TBC than the folk's $(\mathrm{M}=4.56, \mathrm{SD}=0.92), \mathrm{t}(422.46)=3.015, \mathrm{p}<0.01$, Cohen's $\mathrm{d}=0.274$ (small effect size); Mary the Scientist: philosophers' case judgments $(\mathrm{M}=4.53, \mathrm{SD}=0.85)$ were on a par with the folk's case judgments $(\mathrm{M}=4.55, \mathrm{SD}=0.81), \mathrm{t}(481.088)=0.382, \mathrm{p}=0.703$ (ns); Fake barn: philosophers' case judgments $(\mathrm{M}=3.13, \mathrm{SD}=1.38)$ were significantly closer to the TBC than the folk's $(2.35$, 
$\mathrm{SD}=1.28), \mathrm{t}(479.734)=6.458, \mathrm{p}<0.01$, Cohen's d = 0.587 (moderate effect size); Gödel: philosophers' case judgments $(\mathrm{M}=3.97, \mathrm{SD}=1.31)$ were on a par with the folk's case judgments $(\mathrm{M}=3.79, \mathrm{SD}=1.51), \mathrm{t}(473.082)=1.448, \mathrm{p}=0.148$ (ns); Twin Earth: philosophers' case judgments $(\mathrm{M}=, 3.85 \mathrm{SD}=1.34)$ were on a par with the folk's case judgments $(\mathrm{M}=3.91$, $\mathrm{SD}=1.32), \mathrm{t}(481.826)=0.547, \mathrm{p}=0.584$ (ns).

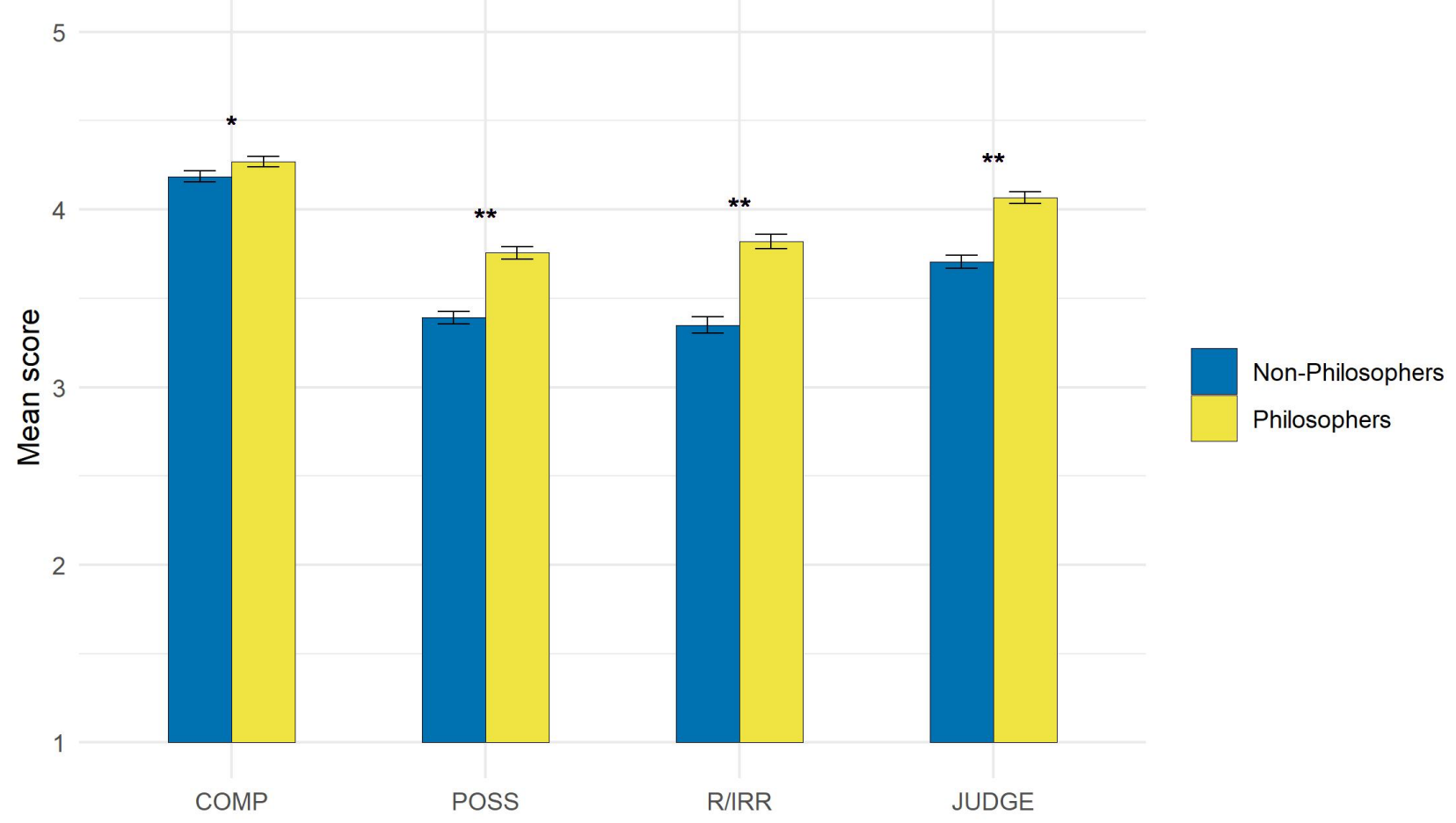

Figure 3: JUDGE task performance. Agreement of subjects with the textbook consensus concerning case judgments in variants of six classical thought experiments (from left to right): Gettier, Chinese Room, Mary the Scientist, Fake Barn, Gödel, Twin Earth. Error bars indicate standard errors. Two stars ( $\left.{ }^{* *}\right)$ indicate a significant difference between the two groups at the $99 \%$ level.

Thus, the difference between lay subjects and philosophers with regard to the JUDGE task was significant in the Gettier case, the Chinese Room, and the fake barn case. The largest group difference was in the Gettier case. In each of these cases, philosophers were more likely to agree with the textbook consensus than the folk. There were no significant differences between the two groups in Mary the Scientist, the Gödel cases, and the twin earth thought experiment. There were no cases in which the folk's case judgments were closer to the textbook consensus than the philosophers' (see Appendix 3 for details). We take these results to disconfirm H4 (JUDGE): philosophers are overall not more likely to 
make judgments in agreement with the TBC than the folk - this time in disagreement with our analysis of the aggregate results (see section 5.1). ${ }^{12}$

Three further aspects of the individual JUDGE results are noteworthy. First, although judgments in Gettier cases are widely perceived as the most robust case judgments there are, in our study philosophers' agreement with the TBC lagged behind their agreement with the TBC concerning the Chinese Room and Mary the Scientist (Gettier vs. the Chinese Room: $\mathrm{t}(241)=8.125, \mathrm{p}<0.01$; Cohen's d = 0.732; Gettier vs. Mary the Scientist: $\mathrm{t}(241)=4.703$, $\mathrm{p}<0.01$, Cohen's $\mathrm{d}=0.4$ ). This may speak for a diversification of the examples often used in some metaphilosophical debates (see for example Williamson [2007]). Second, the big difference between the philosophers and the folk in our Gettier result seems to confirm results obtained earlier by Starmans and Friedman [2012, 2020], but it is in conflict with other studies that provided evidence for the folk converging on the textbook consensus [Nagel et al. 2013; Turri 2013; Machery et al. 2017]. Further research is needed to investigate the reasons for this divergence in the empirical findings. Third, both philosophers and non-philosophers agreed least with the TBC about our fake barn case (means $=3.13$ and $=2.35$, respectively); here the TBC really may have to be revised (see Horvath and Wiegmann [2016]).

Finally let us mention that our individual JUDGE results undermine a concern one may have had about using variants of well-known thought experiments in a study like ours: that philosophers merely recalled the standard case judgments, once they recognized our vignettes as versions of famous thought experiments. Had that been the case, though, philosophers should have agreed more uniformly, and more strongly, with the textbook consensus. The fake barn case in particular shows that that wasn't so.

\subsection{Are the three skills predictive of JUDGE?}

In order to test hypothesis H5, namely whether the skills tasks are predictive of case judgments in agreement with the TBC, we constructed hierarchical models with respondent and question levels [Raudenbush et al. 2002] for all models, because (i) there may be respondent- and question-specific factors that influence respondents' probabilities of

\footnotetext{
12 The mismatch is easily explained: the significant difference in the aggregate JUDGE performance of the two groups is obviously driven by the fairly large effect size differences in the Gettier and the Fake Barn task.
} 
correctly answering a question, (ii) the probabilities for correctly answering the six tasks may be correlated within a respondent due to his/her level of education and/or respondent's individual attributes, or (iii) be correlated within a task due to the nature of the question. Due to the limited number of observations at the task level (as there are only six tasks), and for the sake of cross-model fit comparability, we employ the maximum likelihood (ML) method.

A mixed-effects logistic regression model (with respondent and question as levels) confirmed that (i) philosophers are indeed better than the folk with regard to JUDGE (providing independent confirmation of H4; but see the previous section) and (ii) the three skills (COMP, R/IRR, POSS) are all correlated with a better JUDGE performance (Wald $\chi^{2}(5)=153.42, \mathrm{p}<0.001$; see Appendix 4 for details). ${ }^{13}$ Curiously, however, POSS is negatively correlated with JUDGE: that means that the less willing subjects were to deem the scenarios of the thought experiments possible, the closer their case judgment was to the TBC. That is certainly not something we expected nor something we can easily make sense of. We asked: was this a relation that holds true in both groups (philosophers and non-philosophers)? The answer turned out to be 'no'.

When we ran the same test separately for each group, it turned out that POSS is negatively correlated with JUDGE only in the non-philosophers' group (Wald $\chi^{2}(4)=$ 105.68, $\mathrm{p}<0.01)$. In the philosophers' group POSS wasn't at all correlated with JUDGE. We confess that we don't quite know how to explain these results; they may require further investigation, with perhaps a study more focused on the POSS skill.

In the group consisting only of philosophers, it turned out furthermore that COMP and POSS are no longer correlated with JUDGE. The R/IRR skill ended up being the only skill that was predictive of JUDGE in both groups. ${ }^{14}$ That means that it is crucial for subjects to be able to distinguish philosophical relevant from philosophically irrelevant content for them to make case judgments agreeing with the textbook consensus. The two other skills do not have this status. H5 is confirmed only with regard to the R/IRR skill.

\footnotetext{
${ }^{13}$ The model also showed that being a native vs. non-native English speaker did not have any effect on the JUDGE performance $(\mathrm{p}=0.235)$.

${ }^{14}$ In the non-philosophers' group COMP was also predictive of JUDGE.
} 


\section{Discussion and Conclusion}

The purpose of this study was to determine whether philosophers possess better skills for making case judgments than the folk. We tested this question empirically by testing whether philosophers' case judgments are more informed and informative than the folks', which we determined by measuring the performance of our subjects in three skill tasks: (i) the ability to comprehend the target content of a vignette describing a thought experiment (COMP), (ii) the ability to discern the target content of a vignette describing a thought experiment from its superficial content (R/IRR), and (iii) the ability to accept a broad notion of possibility (POSS). We also tested whether philosophers would be more likely to agree with the textbook consensus of case judgments (JUDGE). Our hypotheses H1-4 stated that philosophers would perform better in each of these tasks. Finally, we tested whether performance in the skill tasks would predict a higher degree of convergence on the textbook consensus (H5).

We consider our results to confirm H2 (R/IRR) and H3 (POSS) and to disconfirm H1 (COMP) and H4 (JUDGE). With regard to H5, we found evidence for R/IRR predicting JUDGE both among philosophers and non-philosophers: subjects who did well on the R/IRR skill were more likely to agree with the textbook consensus of case judgments. We did not find such evidence for COMP or POSS.

Where do these results leave us in regard to the expertise defence? We think that overall, our results do support what we called the informed expertise defence. With regard to R/IRR and POSS, philosophers clearly outperformed non-philosophers. The fact that R/IRR predicts JUDGE (for both philosophers and non-philosophers) goes to show that there is an important link between the ability to distinguish philosophically relevant from irrelevant content to making case judgments that on average agreed more with the textbook consensus. Philosophers didn't have an advantage over the folk with regard to COMP. However we think it actually speaks in favour of philosophers that they did better at R/IRR and POSS despite the fact that the folk overall had as good an understanding of the vignettes as the philosophers.

The fact that philosophers didn't make case judgments in closer agreement with the textbook consensus than the folk in half of our thought experiments may be bad news for the immune expertise defence [Horvath and Wiegmann 2016]. For the informed expertise 
defence, however, the result is not problematic: given that philosophers make their case judgments on a more informed basis than the folk, their case judgments are more trustworthy, even when the folk end up making similar case judgments. Our results, however, do seem problematic for the view that there exists a textbook consensus (for all the cases we considered). Just like Horvath and Wiegmann, we found that philosophers diverged significantly from the 'standard' case judgment in the fake barn case. Crucially, our study provides independent reasons for considering the relevant case judgments trustworthy.

The effect sizes measured in this study were mostly small or moderate, quite in keeping with results produced by experimental philosophy [Machery 2017]. Some critics of the armchair and of the expertise defence have argued that philosophical expertise - if it existed - would have to be shown to be as pronounced as in other fields of expertise, for example playing chess [Weinberg et al. 2010; Machery 2017; Horvath and Koch forthcoming]. Those critics may not be swayed by our results. However it is important not to lose sight of the purpose of the expertise defence: the primary purpose is not to argue that philosophers possess expertise at a similar level as other experts. Rather the primary purpose of the expertise defence is to reject the idea that the findings with the folk straightforwardly extrapolate to the capabilities of philosophers. In order to justify the preference for philosophers as informants about thought experiments, it is not necessary that the magnitude of this advantage is comparable to other forms of expertise (Williamson [2011]; see also Devitt [2011]). All that is required is that philosophers have a significant advantage in the relevant capabilities. That our study shows to be the case.

As we pointed out elsewhere, reports about the failure of the (immune) expertise defence are overblown: many experiments have been conducted with cases from moral philosophy and it's not clear whether the failure of expertise is actually limited to those moral cases or whether this failure generalizes [Schindler and Saint-Germier forthcoming]. But suppose such evidence is forthcoming. Would such evidence not be reason to reject the method of cases tout court, rendering our results largely irrelevant? That depends: both on those future experiments with the philosophers and on how those findings will compare to what we know about other kinds of judgments.

First, for philosophers' case judgments to remain preferable, even in the light of evidence for the unreliability of case judgments, it shouldn't be the case that philosophers 
turn out more susceptible to bias than the folk. That would undermine the plausibility of any kind of expertise defence. Yet even for the bias that has been found among for philosophers in moral cases, no such claim has been made. Second, for the informed expertise defence to be persuasive philosophical case judgments cannot be disproportionately biased, that is, they cannot be more biased than judgments made in other contexts than thought experiments. ${ }^{15}$. If they were, then that would indeed show that there is something fishy about judgments in these kinds of contexts and the whole method of cases should then be avoided (see Machery [2017]). However, to our knowledge, such comparisons are yet to be carried out. ${ }^{16}$

Everything considered, we believe not only that a preference for philosophers' case judgments in the method of cases is justified as things currently stand, but also that - given our results - such a preference could still be justifiable, even if in the future there should turn out to be more direct evidence for the susceptibility of case judgments by philosophers to error.

What if the method of cases is not reliable at all and if it doesn't at all track the truth? Then, of course, any advantage that philosophers may have over the folk with regards to the skills we identified would seem to be epistemically worthless, just like the skills that, for example, astrologers may believe to have when making judgments about one's fate on the basis of stellar constellations are in fact epistemically worthless. We have two thoughts on such an objection: First, we presently do not possess any evidence for the method of cases being not at all reliable. All we have is evidence that case judgments are affected by extraneous factors to some degree or another, mostly when the case judgments are made by the folk. But this is not evidence for zero (or just very little) reliability. Second, we do think that the skills we identified are quite different from skills involved in practices that have no epistemic standing (such as astrology): our three skills have an independent justification. When making a judgment about the content of any kind of text, for example,

\footnotetext{
${ }^{15}$ Ever since the work by Tversky and Kahneman [1974] we know that many forms of human reasoning are prone to cognitive biases. See also Gilovich et al. [2002] and Wilke and Mata [2012] for an overview of psychological work on cognitive bias.

${ }^{16}$ What has been found, though, is that philosophers are much more reflective in making judgments than the folk [Livengood et al. 2010]. The so-called 'cognitive reflection task' used in this study is some ways quite similar to the famous Linda the bank teller example used by Tversky and Kahneman [1974] (in both the most 'intuitive' responses are biased and false).
} 
one must understand what the text is saying. Likewise, in order to make a philosophical judgment about any philosophical text one must be able to discern its philosophically relevant content in order not to be side-tracked by irrelevant details. Any kind of philosophical judgment must also take into consideration a broad range of possibilities. Of course, the skills we identified do not guarantee that the resulting judgments will be reliable with regards to tracking the truth about the concepts in question, such as 'knowledge'. Still, good performance in the skills we identified for informed and informative case judgments are to plausibly necessary conditions for making reliable case judgments. Future studies should therefore control for the skills we identified here.

\section{Acknowledgements}

We would like to thank several anonymous referees, Karen Kiil Brøcker, Anna Daria Drożdżowicz, Chris Mole, Sara Kier Praëm, and Jonathan Jenkins Ichikawa for their critical comments on previous versions of this paper. The paper also profited from feedback we received from the audiences of the Buffalo Annual Experimental Philosophy Conference 2018, the APA Pacific 2019, the epistemology and metaphysics seminar at the Department of Philosophy at Aarhus University and the epistemology seminar at the Department of Philosophy at UBC. We are indebted to Christoffer L. Olesen and Florence So for their help with the data collection and statistical analysis.

\section{Funding Information}

The funding for this study was generously supported by a Sapere Aude project grant from the Danish Research Foundation (grant number: 4180-00071).

\section{References}

Alexander, Joshua, and Jonathan M Weinberg 2007. Analytic Epistemology and Experimental Philosophy, Philosophy Compass 2/1: 56-80.

Bergenholtz, Carsten, et al. 2021. Exclusion Criteria in Experimental Philosophy, Erkenntnis 86/6: 1531-45.

Cohen, Jacob 1988. Statistical Power Analysis for the Behavioral Sciences, 2nd ed. Hillsdale, NJ: Erbaum Press. 
Cova, Florian, et al. 2021. Estimating the Reproducibility of Experimental Philosophy, Review of Philosophy and Psychology 12/1: 9-44.

Devitt, Michael 2011. Experimental Semantics, Philosophy and Phenomenological Research 82/2: 418-35.

Feltz, Adam, and Edward T Cokely 2012. The Philosophical Personality Argument, Philosophical Studies 161/2: 227-46.

Gilovich, Thomas, et al. 2002. Heuristics and Biases: The Psychology of Intuitive Judgment. Cambridge: Cambridge University Press.

Häggqvist, Sören 2009. A Model for Thought Experiments, Canadian Journal of Philosophy 39/1: 55-76.

Hales, Steven D 2006. Relativism and the Foundations of Philosophy. Cambridge, MA: The MIT Press.

Horvath, Joachim 2010. How (Not) to React to Experimental Philosophy, Philosophical Psychology 23/4: 447-80.

Horvath, Joachim, and Steffen Koch forthcoming. Experimental Philosophy and the Method of Cases, Philosophy Compass.

Horvath, Joachim, and Alex Wiegmann 2016. Intuitive Expertise and Intuitions About Knowledge, Philosophical Studies 173/10: 2701-26.

Jackson, Frank 1982. Epiphenomenal Qualia, Philosophical Quarterly 32/127: 127-36.

Livengood, Jonathan, et al. 2010. Philosophical Temperament, Philosophical Psychology 23/3: 313-30.

Löhr, Guido 2019. The Experience Machine and the Expertise Defense, Philosophical Psychology 32/2: 257-73.

Ludwig, Kirk 2007. The Epistemology of Thought Experiments: First Person Versus Third Person Approaches, Midwest Studies in Philosophy 31/1: 128-59.

Machery, Edouard 2012. Expertise and Intuitions About Reference, THEORIA. Revista de Teoría, Historia y Fundamentos de la Ciencia 27/1: 37-54.

Machery, Edouard 2017. Philosophy within Its Proper Bounds. Oxford: Oxford University Press.

Machery, Edouard, et al. 2004. Semantics, Cross-Cultural Style, Cognition 92/3: B1-B12.

Machery, Edouard, et al. 2017. Gettier across Cultures, Noûs 51/3: 645-64.

Nagel, Jennifer, et al. 2013. Lay Denial of Knowledge for Justified True Beliefs, Cognition 129/3: 652-61.

Raudenbush, Stephen, et al. 2002. Hierarchical Linear Models: Applications and Data Analysis Methods. Thousand Oaks, CA: Sage.

Schindler, Samuel, and Pierre Saint-Germier forthcoming. Armchair Physics and the Method of Cases, Inquiry.

Schulz, Eric, et al. 2011. Persistent Bias in Expert Judgments About Free Will and Moral Responsibility: A Test of the Expertise Defense, Consciousness and Cognition 20/4: 1722-31. 
Schwitzgebel, Eric, and Fiery Cushman 2012. Expertise in Moral Reasoning? Order Effects on Moral Judgment in Professional Philosophers and Non-Philosophers, Mind $\mathcal{E}$ Language 27/2: 135-53.

Schwitzgebel, Eric, and Fiery Cushman 2015. Philosophers' Biased Judgments Persist Despite Training, Expertise and Reflection, Cognition 141/August: 127-37.

Starmans, Christina, and Ori Friedman 2012. The Folk Conception of Knowledge, Cognition 124/3: 272-83.

Starmans, Christina, and Ori Friedman 2020. Expert or Esoteric? Philosophers Attribute Knowledge Differently Than All Other Academics, Cognitive Science 44/7: e12850. https://doi.org/10.1111/cogs.12850.

Tobia, Kevin, et al. 2013. Moral Intuitions: Are Philosophers Experts?, Philosophical Psychology 26/5: 629-38.

Turri, John 2013. A Conspicuous Art: Putting Gettier to the Test, Philosophers' Imprint 13/10: 1-16.

Tversky, Amos, and Daniel Kahneman 1974. Judgment under Uncertainty: Heuristics and Biases, Science 185/4157: 1124-31.

Vaesen, Krist, et al. 2013. The Reliability of Armchair Intuitions, Metaphilosophy 44/5: 55978.

Vaidya, Anand 2017. The Epistemology of Modality, The Stanford Encyclopedia of Philosophy, edited by Edward N. Zalta, $<$ https://plato.stanford.edu/archives/win2017/entries/modality-epistemology/>.

Weinberg, Jonathan M, et al. 2010. Are Philosophers Expert Intuiters?, Philosophical Psychology 23/3: 331-55.

Wiegmann, Alex, and Joachim Horvath forthcoming. Intuitive Expertise in Moral Judgements, The Australasian Journal of Philosophy.

Wiegmann, Alexander, et al. 2020. Intuitive Expertise and Irrelevant Options. In Oxford Studies in Experimental Philosophy, edited by Tania Lombrozo, Joshua Knobe and Shaun Nichols, 275-311. Oxford: Oxford University Press.

Wilke, A., and R. Mata. 2012. Cognitive Bias. In Encyclopedia of Human Behavior (Second Edition), edited by V. S. Ramachandran, 531-35. San Diego: Academic Press.

Williamson, Timothy 2007. The Philosophy of Philosophy. Malden, MA: Blackwell Publishing.

Williamson, Timothy 2011. Philosophical Expertise and the Burden of Proof, Metaphilosophy 42/3: 215-29.

Zagzebski, Linda 1994. The Inescapability of Gettier Problems, The Philosophical Quarterly 44/174: 65-73. 


\section{Appendix 1}

- John is a security guard at a warehouse. One night, the alarm bell rings. John therefore comes to believe that someone has just broken in. Unbeknownst to John, the triggering of the alarm was in fact just the result of some electronic malfunction because the technician messed up. However, as it turns out, there was actually a thief who managed to break into the warehouse at the same time when the alarm rang.

- JUDGE: John knows that someone has broken into the warehouse. [incorrect]

- IRR: The technician messed up. / R: The triggering of the alarm was in fact the result of some electronic malfunction.

- COMP: John's belief that there was a break-in is correct. [incorrect]

- POSS: The situation described by the scenario is possible. [correct]

- Imagine a woman named Zoe who doesn't know Arabic. Now imagine Zoe sitting in front of a computer screen that displays Arabic symbols. Zoe is given a big book of instructions. It does not contain any grammar rules of Arabic, but only instructions of the form: 'if you see a string of symbols $S$, then write this string of symbols $S^{* \prime}$. For every symbol she sees on the screen, Zoe's job is to hit the appropriate Arabic letter on her keyboard. What Zoe does not know is that her computer is linked to an internet dating website and that the letters she types are used in communication with a native Arabic speaker in Bagdad. The instructions in the big book are so well-devised that the Arabic speaker in Bagdad does not realize Zoe does not know any Arabic.

- JUDGE: By following the instructions from the book, Zoe understands Arabic. [incorrect]

- IRR: Zoe is a woman. / R: Zoe doesn't know Arabic.

- COMP: The Arabic speaker can tell that Zoe does not know Arabic. [incorrect]

- POSS: The situation described by the scenario is possible. [correct] 
- Imagine some scientists wanted to test the psychology of somebody trapped in a room with nothing to taste. Imagine that a man called Eric was born, grew up in that room, and was fed only by intravenous perfusions. Poor Eric never got to taste anything in his entire life. Because Eric has seen the way people react to good food on TV and how they cringe when biting into lemons, Eric becomes intrigued. He studies all the science there is to know about taste. In fact, he becomes the world's leading expert on the matter and knows exactly what goes on inside the brain when one bites into lemons, for example. When Eric is 36 years old, the scientists start to pity Eric and decide to release him from his room. The first thing he asks for is a lemon. He bites into it and for the first time feels how a lemon tastes.

- JUDGE: Eric learns something new when he bites into a lemon. [correct]

- IRR: The scientists wanted to study Eric's psychology. / R: Eric never had the experience of tasting anything in his entire life.

○ COMP: Eric knows all the science there is to know about taste. [correct]

○ POSS: The situation described by the scenario is possible. [correct]

- Imagine that the director of a famous Picasso museum wants to test the expertise of the visitors to her museum. To this end, she orders forged copies of the museum's Picasso paintings from the world's best forger. The forger is so good that special instruments are required for detecting the forgeries. The director decides to replace all except one of his thousand Picasso paintings with the forgeries. Jerry is one of the visitors. After he enters the exhibition hall, by a curious coincidence, happens to stop in front of the only real Picasso painting in the entire museum. He then thinks to himself 'The painting in front of me is by Picasso'.

○ JUDGE: Jerry knows that the painting in front of him is by Picasso. [incorrect]

- IRR: The director wants to test the expertise of the visitors to her museum. / $\mathrm{R}$ : The forger is so good that special instruments are required for detecting the forgeries.

- COMP: Jerry can tell when the Picasso painting in front of him is forged. [correct]

- POSS: The situation described by the scenario is possible. [correct] 
- Imagine that a man called Bob hears a catchy song on the radio called 'Jingle'. He is told that Jingle was written by Beyoncé, a famous contemporary singer-songwriter. Bob, who does not listen to music much, has never heard of Beyoncé and the only information he has about her is that she wrote Jingle. Now it turns out that the real composer of Jingle is not Beyoncé but her best friend Ceyoncé, who died a few years ago. Beyoncé just found the score written by Ceyoncé, recorded the song, and took credit for it. Nobody is aware of this.

- JUDGE: When Bob uses the name 'Beyoncé' he is talking about the person who actually wrote the song. [incorrect]

- IRR: Ceyoncé is Beyoncé's best friend. / R: The only information Bob has about Beyoncé is that she is the author of the song 'Jingle'.

- COMP: The information Bob associates with the name 'Beyoncé' is wrong. [correct]

- POSS: The situation described by the scenario is possible. [correct]

- Imagine that way out in our galaxy there is a planet very similar to our planet Earth. Let us call it 'Sister Earth'. On Sister Earth, a drinkable colourless liquid flows in rivers and lakes and is externally indistinguishable from water on Earth. This liquid, however, is not composed of $\mathrm{H}_{2} \mathrm{O}$ molecules, but of other molecules that do not exist on Earth. Let us call them XYZ molecules. Now suppose that NASA astronauts managed to visit Sister Earth. The first time they see the watery substance, they shout: 'they have water here too'.

- JUDGE: What the astronauts say when they first see the watery substance on Sister-Earth is false. [correct]

- IRR: Sister Earth is located in our galaxy. / R: The astronauts come from Earth.

- COMP: The watery substance on Sister Earth, despite not being H2O, looks, smells, and tastes exactly like water on Earth. [correct]

- POSS: The situation described by the scenario is possible. [correct] 


\section{Appendix 2}

Age

\begin{tabular}{|l|c|c|c|}
\hline & Min & Max & Median \\
\hline Philosophers & 21 & 77 & 35 \\
\hline Non-philosophers & 20 & 72 & 34 \\
\hline
\end{tabular}

\section{Gender}

\begin{tabular}{|l|c|c|c|}
\hline & Male & Female & Other \\
\hline Philosophers & 176 & 63 & 3 \\
\hline Non-philosophers & 143 & 99 & 0 \\
\hline
\end{tabular}

\section{Philosophy exposure}

\begin{tabular}{|l|c|c|}
\hline Answer & Philosophers & Non-Philosophers \\
\hline I have a PhD in philosophy & 144 & 0 \\
\hline $\begin{array}{l}\text { The highest degree I have } \\
\text { in philosophy is a Master's } \\
\text { degree and I am enrolled in } \\
\text { a PhD program in } \\
\text { philosophy }\end{array}$ & 98 & \\
\hline $\begin{array}{l}\text { The highest degree I have } \\
\text { in philosophy is a Master's } \\
\text { degree and I am NOT } \\
\text { enrolled in a PhD program } \\
\text { in philosophy }\end{array}$ & 0 & 4 \\
\hline $\begin{array}{l}\text { The highest degree I have } \\
\text { in philosophy is a } \\
\text { Bachelor's degree }\end{array}$ & 0 & \\
\hline $\begin{array}{l}\text { I followed at least one } \\
\text { philosophy course at } \\
\text { university but I do not have } \\
\text { a degree in philosophy }\end{array}$ & 0 & 13 \\
\hline $\begin{array}{l}\text { I followed at least one } \\
\text { philosophy course in high } \\
\text { school but not at university }\end{array}$ & & \\
\hline $\begin{array}{l}\text { I did not follow any } \\
\text { philosophy course in high } \\
\text { school }\end{array}$ & 0 & 24 \\
\hline
\end{tabular}




\section{Areas of philosophy}

Answers to the question 'In which of these areas do you feel the most competent as a philosopher? (you can check several boxes)'

\begin{tabular}{|l|c|c|}
\hline & Philosophers & Non-Philosophers \\
\hline Epistemology & 72 & 0 \\
\hline Ethics & 68 & 2 \\
\hline History of philosophy & 57 & 0 \\
\hline Metaphysics & 54 & 1 \\
\hline Philosophy of Science & 70 & 0 \\
\hline Philosophy of mind & 72 & 1 \\
\hline Other & 61 & 0 \\
\hline
\end{tabular}

List of other areas (if mentioned more than once the count is in parentheses):

Logic (8), Political philosophy (8), Political Theory, Aesthetics (6), Human Condition, Common sense philosophy, Philosophy of Language (23), Philosophy of Law, Emotion, Metaphilosophy (3), Phenomenology (3), Philosophy of art (2), Evolutionary epistemology Philosophy of mathematics (2), Continental philosophy, Philosophy of Medicine, Social philosophy, Critical theory, Indian Philosophy, Legal Philosophy (2)

Education level of non-philosophers

\begin{tabular}{|l|c|}
\hline Education Level & Count \\
\hline 1: I did not finish high school & 4 \\
\hline $\begin{array}{l}\text { 2: I finished high school and stopped } \\
\text { studying after high school }\end{array}$ & 103 \\
\hline 3: I have a Bachelor's degree & 97 \\
\hline 4: I have a Master's degree & 17 \\
\hline 5: I have a PhD degree & 2 \\
\hline
\end{tabular}

- 2 participants gave contradictory answers and are not included in this table (one answered the first 3 options and the other option 2 and 3)

- 3 participants answered both option 3 and 4 and are here just counted as option 4

- Participant who had either a bachelor's or master's degree in philosophy was not presented with this question (17 in total)

\section{Language proficiency}

\begin{tabular}{|l|c|c|}
\hline & Philosophers & Non-Philosophers \\
\hline Native speaker & 102 & 211 \\
\hline
\end{tabular}




\begin{tabular}{|l|c|c|}
\hline Advanced or mastery & 133 & 24 \\
\hline $\begin{array}{l}\text { Intermediate or upper } \\
\text { intermediate }\end{array}$ & 7 & 7 \\
\hline
\end{tabular}

Appendix 3

\begin{tabular}{|c|c|c|c|c|c|c|}
\hline & skill & group & mean & sd & p & Cohen's d \\
\hline \multirow[t]{8}{*}{ Gettier } & \multirow[t]{2}{*}{ JUDGE } & folk & 3.07 & 1.38 & \multirow{2}{*}{$<0.01$} & \multirow{2}{*}{0.875 (l) } \\
\hline & & philosophers & 4.15 & 1.04 & & \\
\hline & \multirow[t]{2}{*}{ COMP } & folk & 4.13 & 1.20 & \multirow{2}{*}{0.186 (ns) } & \\
\hline & & philosophers & 3.97 & 1.40 & & \\
\hline & \multirow[t]{2}{*}{ POSS } & folk & 4.16 & 0.92 & \multirow{2}{*}{$<0.01$} & \multirow{2}{*}{$0.528(\mathrm{~m})$} \\
\hline & & philosophers & 4.60 & 0.75 & & \\
\hline & \multirow[t]{2}{*}{ R/IRR } & folk & 2.99 & 1.63 & \multirow{2}{*}{$<0.01$} & \multirow{2}{*}{0.347 (s) } \\
\hline & & philosophers & 3.55 & 1.56 & & \\
\hline \multirow[t]{8}{*}{ ChiRoom } & \multirow[t]{2}{*}{ JUDGE } & folk & 4.56 & 0.92 & \multirow{2}{*}{$<0.01$} & \multirow{2}{*}{$0.274(\mathrm{~s})$} \\
\hline & & philosophers & 4.77 & 0.62 & & \\
\hline & \multirow[t]{2}{*}{ COMP } & folk & 4.48 & 1.08 & \multirow{2}{*}{0.086 (ns) } & \\
\hline & & philosophers & 4.47 & 1.00 & & \\
\hline & \multirow[t]{2}{*}{ POSS } & folk & 3.00 & 1.26 & \multirow{2}{*}{$<0.01$} & \multirow{2}{*}{0.252 (s) } \\
\hline & & philosophers & 3.32 & 1.33 & & \\
\hline & \multirow[t]{2}{*}{ R/IRR } & folk & 3.86 & 1.67 & \multirow{2}{*}{$<0.01$} & \multirow{2}{*}{$0.464(\mathrm{~m})$} \\
\hline & & philosophers & 4.51 & 1.11 & & \\
\hline \multirow[t]{8}{*}{ Mary } & \multirow[t]{2}{*}{ JUDGE } & folk & 4.55 & 0.81 & \multirow{2}{*}{0.703 (ns) } & \\
\hline & & philosophers & 4.53 & 0.85 & & \\
\hline & \multirow[t]{2}{*}{ COMP } & folk & 3.69 & 1.39 & \multirow{2}{*}{0.020} & \multirow{2}{*}{0.212 (s) } \\
\hline & & philosophers & 3.96 & 1.18 & & \\
\hline & \multirow[t]{2}{*}{ POSS } & folk & 2.40 & 1.31 & $<0,01$ & $0393(\mathrm{~m})$ \\
\hline & & philosophers & 2.95 & 1.46 & 20.01 & 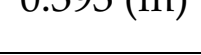 \\
\hline & R/IRR & folk & 3.70 & 1.66 & -001 & $01001 \mathrm{~m}$ \\
\hline & & philosophers & 4.38 & 1.16 & $<0.01$ & 0.400 (III) \\
\hline Fake B & JUDGE & folk & 2.35 & 1.28 & -001 & $0507(\mathrm{~m})$ \\
\hline & & philosophers & 3.13 & 1.38 & $<0.01$ & (m) \\
\hline & COMP & folk & 3.85 & 1.24 & $<001$ & $0556(\mathrm{~m})$ \\
\hline & & philosophers & 4.45 & 0.88 & 20.01 & \\
\hline & POSS & folk & 3.77 & 1.16 & $<0.01$ & $0.287(\mathrm{~s})$ \\
\hline
\end{tabular}




\begin{tabular}{|c|c|c|c|c|c|c|}
\hline & & philosophers & 4.10 & 1.11 & & \\
\hline & $\mathrm{R} / \mathrm{IRR}$ & folk & 3.14 & 1.63 & \multirow{2}{*}{0.016} & \multirow{2}{*}{0.219 (s) } \\
\hline & & philosophers & 3.48 & 1.50 & & \\
\hline \multirow[t]{8}{*}{ Goedel } & JUDGE & folk & 3.79 & 1.51 & \multirow{2}{*}{0.148 (ns) } & \\
\hline & & philosophers & 3.97 & 1.31 & & \\
\hline & \multirow[t]{2}{*}{ COMP } & folk & 4.30 & 1.12 & \multirow{2}{*}{0.866 (ns) } & \\
\hline & & philosophers & 4.28 & 1.03 & & \\
\hline & \multirow[t]{2}{*}{ POSS } & folk & 3.96 & 1.09 & \multirow{2}{*}{$<0.01$} & \multirow{2}{*}{$0.485(\mathrm{~m})$} \\
\hline & & philosophers & 4.45 & 0.93 & & \\
\hline & \multirow[t]{2}{*}{ R/IRR } & folk & 3.02 & 1.72 & \multirow{2}{*}{0.790 (ns) } & \\
\hline & & philosophers & 3.06 & 1.86 & & \\
\hline \multirow[t]{8}{*}{ T-Earth } & \multirow[t]{2}{*}{ JUDGE } & folk & 3.91 & 1.32 & \multirow{2}{*}{0.584 (ns) } & \\
\hline & & philosophers & 3.85 & 1.34 & & \\
\hline & \multirow[t]{2}{*}{ COMP } & folk & 4.67 & 0.72 & \multirow{2}{*}{$0.022(\dagger)$} & \multirow{2}{*}{$0.208(\mathrm{~s}, \mathrm{t})$} \\
\hline & & philosophers & 4.49 & 0.93 & & \\
\hline & \multirow[t]{2}{*}{ POSS } & folk & 3.06 & 1.35 & \multirow{2}{*}{0.664 (ns) } & \\
\hline & & philosophers & 3.12 & 1.37 & & \\
\hline & \multirow[t]{2}{*}{ R/IRR } & folk & 3.40 & 1.69 & \multirow{2}{*}{$<0.01$} & \multirow{2}{*}{$0.339(\mathrm{~s})$} \\
\hline & & philosophers & 3.93 & 1.44 & & \\
\hline
\end{tabular}

$\dagger=$ in favor of the folk

Effect size abbreviations: s=small, m=moderate, l=large. After Hyde (2005): a moderate effect size is between 0.36 and 0.65 (exclusive).

\section{Appendix 4}

Mixed-effects logistic regression models, with JUDGE as the dependent variable.

\begin{tabular}{|l|l|}
\hline Variable & Model \\
\hline Comprehension Skill & $0.098^{*}(0.022)$ \\
\hline R/IRR Skill & $0.099^{*}(0.015)$ \\
\hline Possibility Skill & $-0.099^{*}(0.019)$ \\
\hline Philosopher & $0.374^{*}(0.060)$ \\
\hline Native English Speaker & $0.073, \mathrm{~ns},(0.016)$ \\
\hline Intercept & $0.513^{*}(0.069)$ \\
\hline Log Likelihood & -4.945 .76 \\
\hline
\end{tabular}




\begin{tabular}{|l|l|}
\hline \multicolumn{2}{|c|}{ Random Effects Parameters } \\
\hline Response ID & $0.037(0.023)$ \\
\hline Question & $1.481(42.775)$ \\
\hline Number of Observations & 2.904 \\
\hline
\end{tabular}

Note: * refers to $\mathrm{p}<0.01$ (99\% statistical significance level). Standard error in brackets. There are 484 respondents, each answering 6 questions, in this dataset.

Mixed-effects logistic regression models, with JUDGE as the dependent variable. With only philosophers as subjects.

\begin{tabular}{|l|l|}
\hline Variable & Model \\
\hline Comprehension Skill & $0.046(0.029)$ \\
\hline R/IRR Skill & $0.128^{*}(0.021)$ \\
\hline Possibility Skill & $0.013(0.025)$ \\
\hline Native English Speaker & $-0.083(0.071)$ \\
\hline Intercept & $0.927^{*}(0.062)$ \\
\hline Log Likelihood & -2349.019 \\
\hline \multicolumn{2}{|c|}{ Random Effects Parameters } \\
\hline Response ID & $0.052(0.029)$ \\
\hline Question & $1.426(1.265)$ \\
\hline Number of Observations & 1.452 \\
\hline
\end{tabular}

Note: * refers to $\mathrm{p}<0.01$ (99\% statistical significance level). Standard error in brackets. There are 242 respondents, each answering 6 questions, in this dataset.

Mixed-effects logistic regression models, with JUDGE as the dependent variable. With only non-philosophers as subjects.

\begin{tabular}{|l|l|}
\hline Variable & Model \\
\hline Comprehension Skill & $0.124^{*}(0.031)$ \\
\hline R/IRR Skill & $0.077^{*}(0.022)$ \\
\hline Possibility Skill & $-0.201^{*}(0.028)$ \\
\hline
\end{tabular}




\begin{tabular}{|l|l|}
\hline Native English Speaker & $0.375^{*}(0.113)$ \\
\hline Intercept & $0.284^{*}(0.107)$ \\
\hline Log Likelihood & -2556.483 \\
\hline \multicolumn{2}{|c|}{ Random Effects Parameters } \\
\hline Response ID & $0.007(0.034)$ \\
\hline Question & $1.970(0.807)$ \\
\hline Number of Observations & 1.452 \\
\hline
\end{tabular}

Note: * refers to $\mathrm{p}<0.01$ (99\% statistical significance level). Standard error in brackets. There are 242 respondents, each answering 6 questions, in this dataset. 